\title{
Cellular Psychology Assumption: Based upon Exterior Algebra, It Contributes to Explaining the Variability of the Bioeffects of Magnetic and Electromagnetic Fields
}

\author{
Pierre Le Chapellier, Badri Matta
}

Algology department, Soissons General Hospital, Soissons, France.

Email: pierre.lechapellier@ch-soissons.fr

Received July $18^{\text {th }}, 2012$; revised August $18^{\text {th }}, 2012$; accepted August $22^{\text {nd }}, 2012$

\begin{abstract}
According to its own purposes, including survival, the cell reacts to the conditions of its medium. Such a vital phenomenon implies relational energetics. It includes unconscious psychic energy whose regulating model is the Life and Sense archetype. Its relational power could result from a natural algebraic property of extension. This extension can extend any organic magnitude to 4D event. Thus it allows some perception of the extracellular structure variations. This perception applies to moving forces of the cell signaling activators, through psychic energy. This psychical energy includes a potential, the cell attitude or status, and psychic moving forces, or tendencies. Insofar as the psychical potential is sensitive to proton structures, and the psychic moving forces are excitable by electron exchanges, a phase shift between us may occur. Medium stimulation by adequate magnetic fields could modulate this phase shift in a therapeutic direction.
\end{abstract}

Keywords: Psychical Energy; Bodily Unconscious; Archetype; Philosophy of Nature; Cell Signaling; Sense Order; Causality Order; Static Magnetic Fields; SMF; Electromagnetic Fields; EMF; Topological Thermodynamics; Extracellular Aqueous Medium

\section{Introduction}

\subsection{The Possible Situation of Psyche in the Cells' Biology}

The complex system of communication which manages the coordinated activity of each living cell comprises a cell signaling [1]. Molecular biology has described it according to the model of methodological reductionism. Inherited from the 20th century, this model explained cell signaling and cell behavior merely through combinations of the molecules' behaviors. Energies which take part in the action themselves are ascribed to molecules, by means of the molecular mechanics models which apply to force fields [2]. Consequently cell signaling is supposed to rely only on molecules having a similar action base and primary equivalent agents. On this basis the components of signaling pathways combine and adapt to control each of all the cellular processes operating in very different space and temporal fields [3]. In that way cells can obey the laws of physics and chemistry. However, comparison between physical analysis of the cellular metabolism's distribution and the equation of black body radiation showed that a physically unknown force must exist to ensure the overall functional stability of the living cell

\section{[4].}

During the 20th century, the central dogma in biology was that a gene corresponds to a protein and a function. However, this dogma was invalidated once the activity of the enzyme was defined not only by its context, but in a context which only exists with a history [5]. So the explosion of knowledge about multiple kinds of interacttions in cellular signaling overflowed from the ideas inherited from 20th century.

The comprehension of the biological system thus requires turning to other doctrines that reductionism: at the beginning of 21 st century, with some holism, Systems biology appeared to establish a more global approach of the natural energy links.

Systems biology endeavors to extend molecular biology. It carries out in a holistic way the integration of the signaling networks into their underlying structure [6]. One of its principles is that remodeling the cell microenvironment can generate a cellular attitude. This attitude is defined according to some bio-availability understood as a drug potency, since the processes are studied only in terms of molecules, and not in terms of energy structures giving a direction through a psyche. 
Thus the idea of Systems biology which is to describe the life of a juxtaposition of atoms by only using mathematical tools, poses an ontological problem: according to the Atomism of Democritus [7], as Lucretius exposed it, soul was material. If so, the atoms of a living system had to contribute to its psyche, which implied some Panpsychism ${ }^{1}$, [8]. According to this materialist theory or according to the other theories of living nature, a natural being cannot live in a world without an animation of relations ${ }^{2}$. The purely mathematical physical description of a living organism is thus ontologycally naive ${ }^{3}$.

Quantum Mechanics showed that any moving electron has wave and particle properties. The wave property helps to predict the probability of direction of travel before the electron could be detected as real. Quantum physicists think that, in an electron gun of a TV set, the electron leaves in some kind of limbo, only represented by phantom cohorts. Each of the phantoms explores its own way to the TV screen, but only one electron is actualized on the screen [9].

In a similar way, Nature Philosophy considers that any living organism is defined through a total shape. It is a set of virtual possibilities of which only one may become real under specific medium and state conditions [10]. Thus the organism could have an imaginary function of each of its possible conformations when confronted with a forthcoming reality. At the living cell scale, this function could be linked to cellular perception. Admitted as topological, cellular perception does not imply the cell as a subject and it thus presents a broad absence of subjecttivity ${ }^{4}$.

In this way, the system which manages the activity of the living cell in a given world could be built on the as-

\footnotetext{
${ }^{1}$ Panpsychism attributes a mindlike character to all constituents of material things.

${ }^{2}$ Through the stimulating vital relation, the least blade of grass lives by having on the one hand a relation with the course of the sun and on the other a relation with the moisture of the nourishing earth.

${ }^{3}$ The ontological naivety amounts here to an absence of treatment of the Cartesian aporia. An aporia is a logical dead end, or a radical contradiction. The Cartesian aporia relates to the fact that Descartes tore nature into two, objective matter and all the remainder as subjective, whereas nature, and particularly living nature, proceeds simultaneously with mind and matter.

${ }^{4}$ The absence of subjectivity: Freud said that the psychic experiment is never the real external experiment. Jung added that unconscious material is made with imaginative fantasies which lead nevertheless to real effects. It is the same idea with the probability waves of Quantum mechanics: defined on imaginary complex numbers, they nevertheless lead to real probabilities. Consequently the fitted trace of the psychic experiment in the body can accumulate materially, whether on a level of synaptic connections or a more general cellular level, becoming an objective trace [11].
}

sociation of a causality order and a sense order: causality order is generally referred to the molecular mechanisms. Sense order refers to an energetics which is the psychic energy of the cell organism.

Energetics takes place between the cell purposes and the medium conditions. Peculiar to the sense order, relation energetics constitutes a terrain where the molecular mechanisms are growing with respect to the causality order.

Sense order is assumed to be modulated by the perception of events. When the conditions of the medium make up a new event, a reaction of the cell system can result, within an elementary psychological process which depends on the cell purposes.

Cellular biology generally supposes that the constant remodeling of signalsomes ${ }^{5}$ and signaling networks is due to the variable conditions of the medium. This remodeling could thus result as much from perception accorded to sense order as from physicochemical messages accorded to causality order. What characterizes cellular perception is its translation into an overall energetics which in turn is translated into an architectonic ${ }^{6}$ stress. This stress may act in the underlying structure of cell signaling networks. Environmental variables could in this way, indirectly and qualitatively, exert a transcriptional control of genes, in order to adjust the cellular activity. This applies to simple eukaryotes, like yeast [12]. This is also effective for embryonic cells during differentiation stage, when subjected to exposure to a magnetostatic field [13].

\subsection{The First Eight Points Relating to the Cellular Psychology Assumption}

\subsubsection{Unconscious Psychology}

Cellular psychology refers to a cellular unconscious as it has been constituted since the origins of organic life. Within the functional structures inherited during evolution since the protozoan stage, the cellular unconscious takes part in what Jung called the collective unconscious. All humans today share the collective unconscious. Cellular psychology can be cleared from this human collective unconscious, when it relates to cell adaptation in reaction to extracellular medium conditions, (Jung, 1928, [14]).

\subsubsection{Constitutive Archetype}

According to Jung, (1933, [15]), the unconscious is made

\footnotetext{
${ }^{5}$ The signalsome is on the one hand the system of signaling components specific to each cell which results from the genome and on the other hand any dynamic protein complex on a signaling pathway.

${ }^{6}$ Architectonic: having an organized and unified structure.
} 
up from the archetypes?

Cellular unconscious was thus constituted from a fundamental archetype which is the the Life archetype. However, on a human scale, the Life archetype is called the anima, and anima seems stripped of wisdom. This could give reason to Schopenhauer, $(1819,[18])$, who wrote about the absurdity, stripped of sense, of the Will to live, (der Wille zum leben). But Jung observed that the young chaotic eruptions of anima can also fasten on to a hidden wisdom. With the maturity of human beings this hidden wisdom appears more easily. In biological systems stripped of any thought, this hidden wisdom also exists, according to a sense potential. From the definition of archetype, this sense potential can be identified with the image which leads to the form that any living matter existing in a given world tends, (mysteriously), to fulfill. The Life archetype thus conceals a sense potential including some hidden wisdom. In this way, at cellular level, the structural source of cell unconscious may be called the Life and Sense Archetype.

\subsubsection{The Image as an Envelopment}

On the one hand basic physiological processes can generally be described in terms of real numbers because they do not have any psychic quality. On the other hand the life of any organism, including the cell life, is indissociable from the psyche. Cellular life could particularly relate to psyche through the identity of sense and unconscious image. This identity is such that when an image is formed, sense is clarified [19]. But this kind of image is not an image like the representation images which are formed in the brains of animals or men.

This kind of image is like an envelopment which gives a directed sense to biological action. This envelopment results from a cellular perception in reaction to the conditions in the medium. Perception may contribute to an "image" that translates into an overall trend \& orientation stress exerted on the real biological magnitudes. Its description by means of abstractions may be brought close

\footnotetext{
${ }^{7}$ The archetype, according to Jung, is not a primal image. It is rather the beginning of the type which is used as model. It is thus a virtuality whose power is to preform perceptive experience. It is thus also a propensity, (an inclination), always to reproduce the same things. It is thus a print, printed many times, of the subjective reactions. But more than simple prints of experiences, archetypes behave as energetic force centers because they operate according to tendencies which urge the subject to renew the same experiments. This idea agrees with a strong idea of the philosopher Bergson, according to which living matter, and thus the cell itself, is a center of biological forces, [16]. By applying to it the Jung concept, this biological force field tends to be stressed and oriented by a higher psychic force center, i.e. an archetype, associated with a form: on all scales, archetype is the principle of the form a drive surge will take on. Each instinct takes on a situation form by filling an image which has fixed properties, [17]. At the physiological instinct scale, archetype, this collective dominant, takes roots directly in material organism. Archetype is a fact of existence which is based on the particularities, (specific characteristics), of the organized living systems themselves.
}

to the concept of directed magnitude which is inherent in complex numbers, as it will be shown further on.

The envelopment also corresponds to a sense contribution which can be a direction contribution. It is just like the mathematician's Analysis situs ${ }^{8}$ which makes it possible to bring out a sense, making it possible to solve certain equations.

So the psyche of organic life is a kind of imagination of relations which is translated into relation energetics. Thus it cannot be described merely with real numbers but depicted with an equivalent of complex numbers, probably associated with an equivalent of the mathematical Analysis situs.

\subsubsection{The Bodily Unconscious}

Cellular psyche cannot by itself include subjective evaluations based on affects, feelings or thoughts, because its nature is only that of a relation energetics.

It is thus epistemologically possible to reduce cellular psyche to the bodily unconscious which tends to envelop and direct the objective magnitudes of the cell's biomaterials, in a manner which is completely stripped of subjective evaluations.

The bodily unconscious, or corporeal unconscious, envelops living matter, and hence the body's cells [22, 23]. It is the complementary side of the psychical unconscious which envelops the human reason:

The collective unconscious is, at human level, all the irrationality which does not coincide with reason and which is around it. It is thus a kind of envelopment which includes two layers. The first one is the personal layer which stops with the earliest infantile reminiscences. Around this is the second one. It is the collective layer which includes the pre-infantile time, i.e. the ancestral experiment.

The certainty that bodily unconscious is really the most physical part of collective unconscious is based on the antique concept of the Great Mother which in fact is derived from the Life archetype. The Great Mother is the archetype principle of the world's matter [24]. She was supposed to offer an invigorating experience to the live individual who could achieve a direct vibratory relation with her. But his archetype principle is preexistent to human life. According to this principle it is since the origin of life that the Life archetype constituted the bodily unconscious which applies today to cellular psychology.

\footnotetext{
${ }^{8}$ Analysis situs, situation analysis, is a mathematical tool of topological nature, also known as general topology. For his inventor, Henri Poincaré, $(1890,[20,21])$ supported by the work of Leibniz of 1679, (relating to the collections of related mathematical objects called varieties), the goal was to allow, by a kind of logical envelopment (resulting from non-Euclidean geometry with complex functions), the release a sense, (resulting from singular points of enveloping surfaces), in order thus to contribute to the solution of differential equations having no traditional analytical solutions.
} 
It is assumed that bodily unconscious includes the animated life which is oriented and delimited by the inhabited environment. At cell level it translates into a sense order which ensures, through causality order, the functional stability of the cellular life.

\subsubsection{Sense Order and Causality Order}

Cellular psychology relates to the sum of the sense order and causality order. Sense is defined here as the selfsignificance of action or existence in a given world; it is the manner in which the purpose or finality is translated biologically. At cellular scale, sense order brings into play images which are not so much images as a kind of envelopment in which some "simple imagination" could have the main role:

At cell scale, there is neither thought nor representation-image coming to extend the causal mechanics of perception. There is not this subjective soul distinct from the objective living matter of which Descartes said: "It is the soul which sees, not the eye," [25]. It remains nevertheless that Descartes, (in the same text), had an intuition of the "imaginary" device that live cellular matter could use to see its environment: "The distance or depth of an inaccessible item $\mathrm{X}$, that the land-surveyor cannot therefore measure directly, can always be appreciated by him by means of a natural geometry $\cdots$ according to a very simple imagination which is an envelopment."

After having torn nature into these two apparently irreconcilable parts that are objective matter in extension and all the remainder described as subjective, Descartes thus had a presentiment of what allows their simultaneous rational existence; it is an envelopment. And while through quantum mechanics causality order should rest on the body of complex numbers, (real + image), through an envelopment principle sense order should rest on a more complex reality, (real + images of situation). In that complex reality, imagination has an enveloping role, by means of a four dimensional, 4D, cell extension which can be depicted by exterior algebra.

\subsubsection{The Assignment of Sense}

It is stated that a cellular organism living in its world functions with a sense order whose nature is unconscious and non-subjective. Sense order corresponds to "imaginative" psychic energies whose potential can be felt early or late on real forces.

Cellular psyche is thus primarily a vital phenomenon whose support is the non-psychical nature of the medium, [26]. Sense order which is associated with an attitude, a state or a behavior, can thus vary according to the nonpsychic conditions of the medium. Consequently the sense assignment, as it results from the composition of the psychic energy, could be modulated by a change in the external medium structure driving it to a 4D perception. This has been shown as a possible bioeffect while varying the topological structure of the extracellular aqueous medium, by means of magnetic fields or electromagnetic fields [8].

\subsubsection{Sense and Cell Conformation}

When things may acquire some sense, this generally translates into a behavior, or an attitude, a change in direction, an orientation in the $4 \mathrm{D}$ inhabited space. In the living cell, sense is translated by an orientation of the magnitudes which relate to the functioning, survival, or other purposes of the organism. By an effect of the overall architectonic stress which results, this magnitude orientation generally leads to the making of a form.

\subsubsection{The Cell's Psychic Energy as a Relation Energy}

The adaptive reaction of the cell to the medium conditions permanently creates a psychic tension which is relation energy. This psychic energy can either be potential and result in an attitude or status, or be present and result in psychic moving forces, or tendency. Jung indicated that it is the attitude which determines whether or not the psychic moving forces [13] are effective. Consequently the brain does not contain memories by itself, as the philosopher Bergson points out [27], because the psychic energy conformations intervene, [28].

In a tissue, when cells are in contact and have gap junctions, their relation energy is generally more collective and physically determined by messenger signals.

\section{Psychical Energy of the Cell}

\subsection{The Forsake of the Nervous Energy Concept}

After his meeting with Sigmund Freud in 1880, the Austrian physiologist Joseph Breuer came to conceive the nervous system as a reservoir of potential energy, the nervous tension, [29]. This reservoir is filled with energy by excitations, affects, organic pressures, and it empties by motor pathways, appeased emotions and instincts. Breuer observed that nervous energy can be structural or circulatory. Freud then assigned free circulatory nervous energy to unconscious psychic processes and approximately all the remainder to conscious processes, [30]. Thereafter the major and divergent disciple of Freud, Carl Gustav Jung, would forsake nervous energies in favour of the more general concept of psychic energies, [28].

\subsection{Psychic Energetics}

Psychic energies are quantities which exist in forms which can be transformed between themselves or with respect to physical energies. They are either current 
forces or potential conditions. A psychic condition results in a cell attitude. It is this attitude which makes the psychic moving forces which apply to the physical processes effective or not. As present psychic energy is made of moving forces which tend to exert a physiological stress, most unconscious psychic functions can be supported by basic physiological processes which do not a priori have any psychic quality [31].

Through the moving forces, psyche and matter are stated to be in permanent contact, without the nature of their relation being able to be disentangled with precision. Jung represents this relation as that of two cones whose tops touch and do not touch themselves in a zero point [32]. See Figure 1. This zero point can evoke either intermolecular empty space or the Static Void which has the static property of action-reaction.

\subsection{Role of the Negative Reality in the Cell Attitude}

The conditions which determine the unconscious potential state are characterized by the being non-being pair [33]. The psychic potential which results in a cell attitude thus depends on a negative reality. This includes the 4D structure of extracellular intermolecular space. It also includes the total form of the cellular organism which is the whole of its non-realized conformational virtualities. This total form in negative form could be linked to genome sequences shown as "useless" [34].

Within Jung's meaning, Energetics forms a complement to the mechanical approach. Jung stated that, because they are indissociable, psychical and biological energies tend to organize with a view to a purpose or an end. In reaction to the medium conditions, this finality is the reason why the cell does have a definite action. This finality which forms the sense of action is temporally anticipated. It goes on according to advanced waves ${ }^{9}$ which are inscribed in the cell attitude.

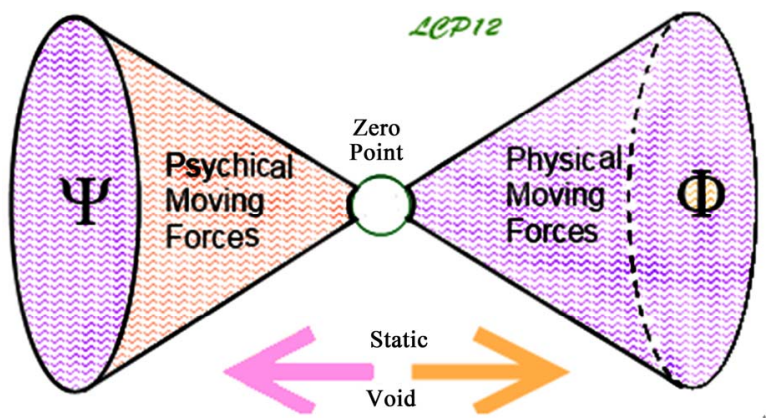

Figure 1. Jung's idea about the kind of relation between physical and psychic moving forces. This relation would be that of two cones whose tops touch and do not touch each other at a zero point. This zero point evokes either the Static Void or intermolecular space. By definition the Static Void has a physical property, that of action-reaction.

\subsection{Libido as Overall Biological Energy}

If we admit that a psychic process is a vital process, psychic energy logically forms part of an overall biological energy which includes mind-body relations. This overall biological energy was defined by Jung as libido.

The energy of the cellular psychology is thus included in that of the cellular libido. The vital nature of cellular libido has only the physiological processes as horizon, even if the exact nature of relations between psychical and body processes escapes largely from experiments ${ }^{10}$ [35].

\subsection{The Associated Extensive Character's Role}

The philosopher Kant stated that physical energy is an intensive magnitude, because it has a degree of influence on sensors [38]. Current science states that physical energy is an extensive magnitude, because it is proportional to the volume $\Delta \Omega$ of the element considered. But Jung noticed that energy can also present an associated extensive character if it is able to give a dynamic determination to the phenomenon. Indeed Russian physicist Landau showed in 1937 that, at the time of transitions between phases, an order parameter which is an extensive magnitude intervenes. This magnitude is null in the first phase which is generally most symmetrical and non-null in the following phase, the least symmetrical which becomes the most directed [39].

In crystals, this order parameter is a complex scalar field which acts as an effective wave function. In psychic energy, the correspondent associated extensive character would be that of a mass whose physical magnitude is that of an imaginary mass [40].

In wild nature, physical energy changes its form when it follows its slope by producing what is called natural

\footnotetext{
${ }^{9}$ Advanced waves and delayed waves: In contrast, the law of FechnerWeber is a mechanical law of psychobiology. It states that the magnitude of a stimulus must be geometrically increased so that the magnitude of a feeling be arithmetically increased. Compared with a biological action oriented according to advanced waves, this stimulus is physically present according to delayed waves. That is why the law of Fechner-Weber does not apply in energetics - including when it concerns the sense of a physiopathological pain that the patient can evaluate on a visual analogical scale, VAS, of $10 \mathrm{~cm}$.

${ }^{10}$ Theories relating to the mind-body relation go back to Aristotle who considered that there are two aspects of the same entity, unlike Descartes who regarded mind and body as separate, and Leibniz who believed in separated aspects, but with processes equipped with parallels. Evaluations of the mind-body relation by experimental psychology hardly contribute to the explanation when using the causal law of Fechner-Weber. On the other hand the existence of a narrow parallel between physical and psychic processes was also justified by the phenomenological conception of philosopher Merleau-Ponty [36]. According to him the mind-body relation is realised every time in the movement of existence when living in a world. Such an aphorism generalizes the philosopher Malebranche's opinion which is that the mind-body relation is realised at the time of action [37]. Nevertheless, in 2011 there is very little experimental knowledge on this relation.
} 
phenomena. The Jung's idea is that when a form of physical energy associated to a volume $\Delta \Omega$ changes, the characters of the former form are transferred in a way that libido can perceive.

Libido, the overall energy of living matter, can only use the natural laws which apply to physical and chemical energies. So when energy changes its form, an extensive character associated with the former psychic energy form will transfer into the new form of energy. When the libido transfers energy from one form to another, it also transfers characters associated with the former form. At cellular level energy conversions can operate by associating concrete data with a transferred character which becomes equivalent to a symbol. This symbol is needed to act on the Life and sense archetype then causing an "image" production. This image results in a sense clarification of the cell energetics.

\subsection{Energetics and Sense Contribution}

Cellular psychology is an energetics included in libido. It consists of a potential energy which is a psychic condition leading to a cell attitude, and moving forces leading to a tendency. Attitude may be appreciable in a thermodynamic way including entropy ${ }^{11}$, (which means that the cell libido can be as much will to live as will to decline or self-destruct).

Cellular psychology is based upon the reaction of the cell organism to variable conditions of its microenvironment. Biological reaction is carried out in order to counterbalance any influence contrary to an organism's purpose. An influence leading to a darkening of image or to obscuring vital sense is equivalent to a sense loss. Conversely, what allows an adapted attitude of the cell is a sense contribution: When, by means of the archetype, an "image" is formed and "vital sense" is clarified, the sense contribution becomes assigned in terms of psychic energetics, (attitude and moving forces).

\subsection{Towards a Mathematical Approach to Psychic Energetics}

The physics of the 20th century highlighted the fact that light behaves at the same time as a wave and a particle and that it is the same for matter in general. The mathematical unity of this paradox led to abandoning the former Causal mechanics in favour of Quantum mechanics. The latter defined probability wave fields that are encountered only on the body of complex numbers, $\mathrm{Cn}$, and not on the body of positive real numbers, Rn. And the same went for Analysis situs. Since cellular perception

\footnotetext{
${ }^{11}$ Entropy measures the energy part of a system that disorder makes unable to provide work. A sense contribution which restructures a reality is thus a negative entropy.
}

and image formation proceed through an envelopment with some organic equivalent of Analysis situs, those psychic energetics principles could be depicted upon an equivalent to the body of complex numbers, with the word complex having the mathematical sense of (real plus imaginary).

The philosophy of Nature of Merleau-Ponty [41], leads to this idea of the deployment in $4 \mathrm{D}$ of the organism's being-envelope ${ }^{12}$ on the occasion of each event related to its life and purposes. As 4D means four dimensions, it implies the presence of a temporal thickness joined to the 3D space. That is, the living being present includes its pre-personal history whose memory is recorded in the being's matter, as well as anticipations relating to virtualities inscribed in the total form of its non-being.

This temporal thickness is part of the 4D space inhabited by the cell through its extension property.

\section{Complex Numbers and Sense Order}

\subsection{The Appearance of the Root of Minus 1}

In 1545, Jerome Cardan, (mathematician, but also doctor and inventor of the universal joint) published Ars Magna, (The Great Art) [43]. The work is particularly relative to possible means of solving polynomial equations of the $3 \mathrm{rd}$ degree. The method which allows it is said to have been invented by a man named Tartaglia, (the Stammerer)

\footnotetext{
${ }^{12}$ The concept of being-envelope of the organism is an essential asset of the philosophy of Nature. A broad description was given by Le Chapellier, $(2011,[10])$, around the four following points:

1) The concept of a simple or complex organism allows the Cartesian aporia, to be overcome (see n.3): to logically suture the tear of Nature opened by Cartesian dualism, the mathematician A. N. Whitehead, $(1925,[42])$, stated that every natural being has an organism and that any organism presents properties of endurance, stability, and extension.

2) The extension property destroys the idea of simple localization in space-time. It brings into play an extension, or striding over, which differs from the fringe idea which is possibly associated with the exterior differential form of mathematics. It supports the nature of cellular perception because it makes organism have a being-envelope to exist in the world and that in this envelopment events can be presented.

3) Because the being-envelope acts on the sense order at the time of events, a constant modulation of the interior relations within the organism is caused. This constant internal modulation is what ensures both the stability of the organism and its adaptation to the changing world. And this internal modulation is also what allows the organism to be robust and enduring.

4) The extension property also leads to the following idea: the topological structure of the intermolecular vacuum of the extracellular aqueous medium is adjustable by certain physical events. Its perception can involve a modulation of the sense order. Linked to psychic energetics and finality, sense order forms the overall terrain where the causal forces relating to the mechanics of signaling networks grow. While being an enveloping terrain, sense order is structural. Translating psychic energetics, it globally orients the internal relations of the cellular organism, even including epigenetic choices.
} 
himself inspired by a third mathematician of the Italian Renaissance, named Bombelli.

This method was as follows: introducing two numbers $p$ and $q$, the polynomial equation $a x^{3}+b x^{2}+c x+d=0$ is expressed as an equation of the form: $z^{3}+p z+q=0$, whose discriminant $\Delta=q^{2}+4 p^{3} / 27$ can be calculated. This discriminant $\Delta$ can be positive, null or negative. Its solutions, which can be real or imaginary, often require the use of imaginary numbers based on the root of minus one, $\sqrt{-1}$, which can even lead to real solutions. Cardan called these strange and sometimes misleading numbers "sophistical quantities", before Bombelli clearly indicated them as "impossible numbers". Afterwards Descartes proposed into 1637 to call them "imaginary numbers", clearly marked by the sign $\sqrt{-1}$ [44].

After the English mathematician John Wallis 1685, it was the Danish surveyor Caspar Wessel who in 1799 would give a geometrical interpretation of these imaginary quantities [45]. He did it after the Swiss mathematician Leonard Euler proposed into 1777 to use the notation " $i$ ", ( $i$ for imaginary), instead of $\sqrt{-1}$. Euler then stated the equation: $i^{2}=-1$, starting from $i^{2}=\sqrt{-1} \times$ $\sqrt{-1}=-1$. On the basis of these ideas, the French mathematician Jean-Robert Argand, (1806, [46]), stated that the operator $i=\sqrt{-1}$ in fact means $1 / 4$ turn rotation, or $\pi / 2$ rotation. This rotation applies to a real magnitude which becomes an "imaginary quantity". And consequently the quantity $i^{2}=-1$ must mean $1 / 2$ turn rotation, what is the real magnitude's U-turn. Argand deduced from this that any magnitude which corresponds to what was called an imaginary quantity, (real + image), constitutes in fact a directed magnitude, (a magnitude having an orientation, and thus a sense).

Argand attempted to apply this idea in order to extend to these directed magnitudes the old Euclidean theory of the relationship between simple magnitudes.

\subsection{The Complex Number, or Directed Magnitude}

Thereafter Gauss, (1831, [47]) introduced the operator " $i$ " instead of $\sqrt{-1}$, and renamed "imaginary quantities" as "complex numbers", which consist of the sum of a real part $a$ and an imaginary part $i b$, thus having the form: $(a+i b)$.

It consequently appeared that any complex number is a magnitude directed by an extension. It is possible to see on the left part of Figure 2 that, in the complex Gauss plane, any complex number corresponds to the effect of a real linear magnitude extended into a surface. This extension is then the cause of a rotation which results in a magnitude orientation.

In the Gauss complex plane which was supposed to

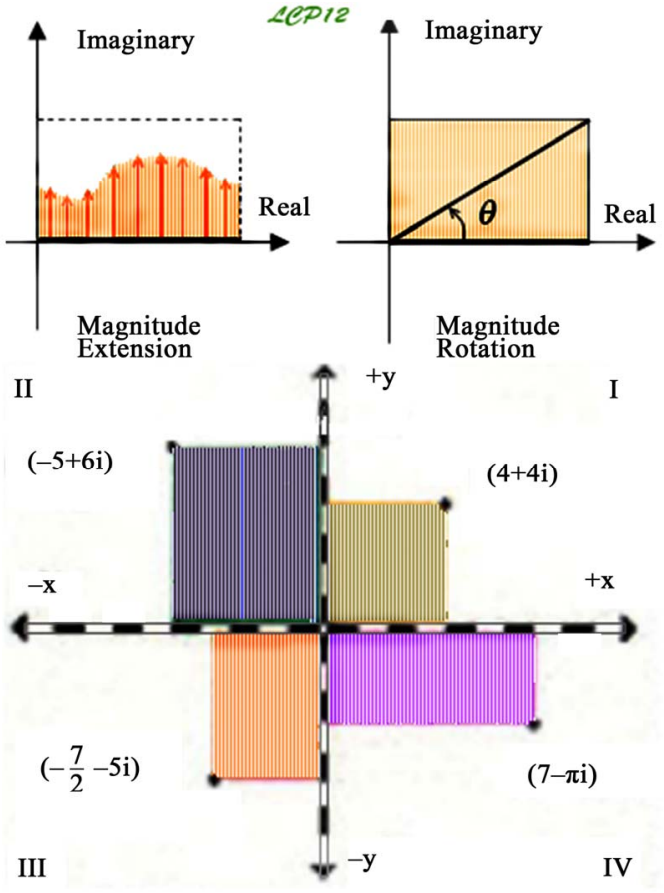

Figure 2. Compound physical actions in the complex \& cognitive Gauss plane. The upper part of the figure shows a real linear magnitude which is extended into a surface, through the direction and effect of an imaginary magnitude. This extension is then the cause of a rotation with a $\theta$ angle, resulting in a magnitude orientation. The lower part of Figure 2 shows not only the real $x$ and imaginary $y$ axes in the Gauss plan, but also a rotation sense, indicated by the successive quadrants, from I to IV.

correspond to the cognitive plane, each complex number indeed represents a single combination of extension and rotation [48]. But this plane does not correspond to ordinary visible space [49].

A more academic approach to the complex plane of Argan-Gauss is represented in Figure 3. One can see that the imaginary quantities $i b$ involve extension and rotation of the real quantities $a$ and $b$ which thus become the directed magnitude $(r, \theta)$, associated with any point $\mathrm{M}$ of the plan:

The number $z=(a+i b)$ associated with the point $\mathrm{M}$ is also a scalar $r$ which is a "modulus" associated with an orientation angle $\theta$. This is written:

$z=r(\cos \theta+i \cdot \sin \theta)$. Starting from Euler's formula, $e^{i \pi}=\cos \theta+i \cdot \sin \theta$, it becomes: $z=r \cdot e^{i \theta}$. The fact that $e^{i \pi}=-1$ refers to the half turn case, where $\theta=\pi$.

\subsection{The Problem of Extension into Space}

It remains that cellular psychology is concerned with the being-envelope which is an extension of the organism's real magnitudes in 4D space, since it is this that can modulate the sense order by producing oriented magnitudes. 


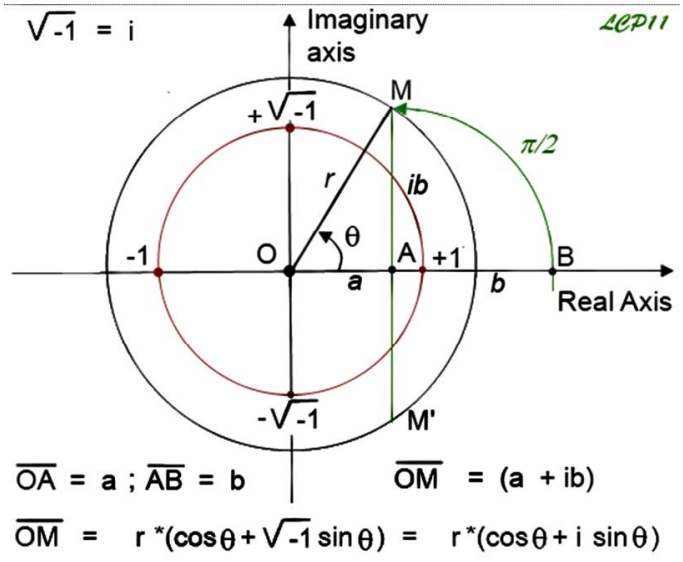

Figure 3. The Argand-Gauss Complex Plan. Let a quantity $b$ measure the distance between points $A$ and $B$ laid out on a real axis which is here the horizontal axis. By applying a $\pi / 2$ rotation, or $1 / 4$ turn, operated by " $i$ ", b becomes an imaginary quantity $i b$. In this way quantities $i=\sqrt{-1}$ and $-i=-\sqrt{-1}$ are at the same time operators and quanti- ties +1 and -1 having undergone a 1/4 turn rotation which brought them on to a secondary axis perpendicular to the real axis. The figure shows that any point $M$ in the complex plan, (real + image), is a complex number $(a+i b)$. The point $M$ ', symmetrical to $M$ compared with the real axis, is defined by the conjugate complex number $(a-i b)$. The sum, or product, of two conjugate complex numbers $M$ and $M$ ' gives a real number.

The extension of a real magnitude into a 2D surface or a $3 \mathrm{D}$ volume is not enough to describe a biologically oriented magnitude. The extension in 4D space equipped with its temporal dimension is needed.

In 1813 Argand had tried to extend to the 3D space the directed magnitudes that are complex numbers. But for a long time there were mathematical difficulties in going from extension into $2 \mathrm{D}$ surface to extension into $3 \mathrm{D}$ volume.

Argand's proposal could be carried out only in 1844 , after the revelation ${ }^{13}$ that William Hamilton had about quaternions, [50]. The quaternion is like a super-complex number which is written: $q=(w+x i+y j+z k)$. Here $w, x$, $y, z$, are real numbers, while $i, j$ and $k$, are the operators of a direct trihedron and are all similar to $\sqrt{-1}$. Hamilton thus stated that: $i^{2}=j^{2}=k^{2}=-1$. The fundamental idea of Hamilton is that a quaternion is a number which comprises a scalar ${ }^{14} \mathrm{w}$ noted as real, as well as the three coordinates of a vector, $x i+y j+z k$, noted as imaginary.

The philosopher Hegel, (1817, [51]), had been struck

\footnotetext{
${ }^{13}$ Revelation: it was after years of reflexion on this question without finding the right solution that on October 16, 1843, when William R Hamilton and his wife were walking in the proximity of the Royal Channel of Dublin, the unconscious provided him, in an illuminating flash, the perfect answer. Hamilton, grateful, engraved the received answer in the stone of the bridge located near this place.
}

by Argand's concept of directed magnitude, because this concept seemed apply perfectly to the light ray. But the light ray comprises both a direction in space, according to a vector with three coordinates, and at the same time a scalar quantity, relative to its energy. To be defined on a macroscopic scale, a real ray of light thus required a Hamilton quaternion and not an Argand directed magnitude.

To describe the electromagnetic field, Maxwell, (1873, [52]), forsook the analytical calculation carried out starting from the Cartesian coordinates method. He preferred to reason on vector spaces. He started from the Hamilton principle according to which each point of the vector field is equipped with a scalar quantity and a direction referred to three coordinates.

This principle more generally applies to form-adoption. Philosopher Simondon, (1962, [53]), observed over a long time that form-adoption, (that is to say individualtion), requires the association of a scalar potential $w$, (which is a quantitative energy), and a vector potential $V$, (which is a germinative structure).

Physical or biological, individuation, as a form-adoption, requires organized rotations of the vector fields relating to forces. The Hamilton method presented limits for a mathematical description of these phenomena. These limits were passed by the use of the extension theory of Grassmann, (1844, [54]), which provided the bases of vectorial analysis. The Grassmann theory also offers a way to describe the biological magnitude extension and orientation due to the event happening in 4D space.

\section{Grassmann Exterior Algebra and Sense Order}

According to Whitehead, (1920, [55]) and followers, any animated organism has the property of extension. This philosophical concept refers to the mathematical theory of Grassmann that Whitehead himself had explained in details in an algebra treaty [56]. The functioning of cellular psychology with the extension property could thus be explained by using the extension theory of Grassmann.

The beauty with which the mathematical structures invented by Grassmann describe the physical world reflect the beauty of nature. This could be because Grassmann's analysis method is in conformity with nature, for several reasons: Firstly Grassmann method is based on a theory of the mathematical forms which held account of the philosophy of nature suggested by Schelling and Hegel [57]. Secondly its method erases the difference

\footnotetext{
${ }^{14}$ Scalar: this word comes from the English word scale, for: scale of values.
} 
between the analytical and synthetic treatments of geometry. Thirdly its method is fastened to a qualitative consideration of geometry, offering a place to invariants' concept.

The exterior algebra of Grassmann which on which contemporary vectorial algebra is based, can also apply to biology: It makes it possible to understand the natural mechanism by which the extension property of organisms acts, so that interior biological magnitudes may become oriented and stressed by an architectonic. But even so the Grassmann theory does not completely satisfy the wish of Leibniz, (1679, [58]). That wish was to represent to the mind and naturally, although without figures, everything that depends on imagination.

The basic concept in the Grassmann theory is extension. It acts according to a geometrical interpretation of the algebra whose fundamental operation is the exterior product: An algebraic element can be extended by the effect of its exterior product with another element, to form an element of a higher nature.

For example a point $\mathrm{A}$ is said to be of grade 1. By its exterior product, point $\mathrm{A}$ can be extended with the help of a point $\mathrm{B}$ to form the straight line which joins $\mathrm{A}$ and $\mathrm{B}$. This line $\mathrm{AB}$ is of grade 2 and is antisymmetric, (according to $\mathrm{AB}=-\mathrm{BA}$ ). It can be extended by its exterior product with a point $\mathrm{C}$, the result being the $\mathrm{ABC}$ plane which is of grade 3 , and so on towards higher space dimensions [59]. Elements created by the exterior product constitute subspaces of the linear space considered.

From a vector $\boldsymbol{x}$ extended while following vector $\mathrm{y}$, the exterior product algebraically results in a bivector, $\boldsymbol{x}^{\wedge} \boldsymbol{y}$. This bivector geometrically corresponds to the surface of the parallelogram having for sides vectors $\boldsymbol{x}$ and $\boldsymbol{y}$. Its exterior product by a vector $\boldsymbol{z}$ results in the trivector $\boldsymbol{x}^{\wedge} \boldsymbol{y}^{\wedge} \boldsymbol{z}$ which geometrically corresponds to a parallelepiped. Such a resulting product $\boldsymbol{x}^{\wedge} \boldsymbol{y}^{\wedge} \boldsymbol{z}$ can be regarded as a "Grassmann number".

It can be said to be a hypercomplex number which comprises "a body", (its quantitative scalar) and "a heart", (all the qualitative remainders, including the angles, direction and sense) [60]. From that point, Cartesian aporia which split nature between objective matter and all the remainder may thus be solved by the logic of numbers described according to the Grassmann theory of extension.

When it was applied to organisms living in a world, the Grassmann theory of extension became the Whitehead theory of extension. Mathematician and philosopher Alfred North Whitehead offered a logical description of the extended space which supports the relations from which a vital energetics results [55]. This extension ensures a non-cognitive capture of the aspects of the world for oneself [61]: on the occasion of an event, the cell, (or any more complex organism), reflects larger enveloping models in itself, which may cause modifications in its own being. As can be seen in Figure 4, the event is depicted as an equivalent of a quadrivector of the Grassman exterior algebra. In this type of $x^{\wedge} y^{\wedge} z^{\wedge} t$ Grassmann number, the duration $t$, i.e. the temporal thickness, is the primordial line [61]. It is it what confers a "vectorial tonality" on the perception of the event by the living cell [62].

Grassmann said: "The element which causes extension changes crosses a diversity of states whose overall form constitutes the field of the extensive magnitude. On the other hand the generation of the intensive magnitude provides a continuous series of equal states of which the quantity is precisely the intensive magnitude" [63]. There is thus a contrast between what is equal within the intensive quantities and what is different within the extensive magnitudes. Another contrast exists between discrete molecules and continuous intermolecular space. During the natural process of generation, the dialectic between these contrasts contributes to creating the architectonic system of the organism [64].

The architectonic of the cell's psychic energy could thus result from a dialectic between the extensive magnitude

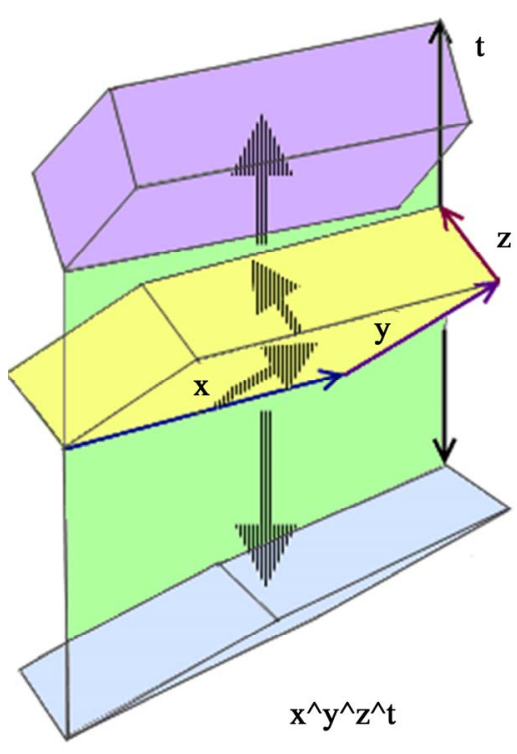

FUTURE

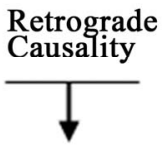

PRESENT

Subspace

$\mathbf{x}^{\wedge} \mathbf{y}^{\wedge} \mathbf{z}$

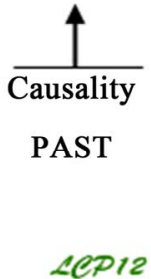

Figure 4. The Event as a Grassmann quadrivector. A quadrivector $x^{\wedge} y^{\wedge} z^{\wedge} t$ is built from a vector $x$ extended following vector $y$ into a parallelogram, extended following vector $z$ into a parallelepiped. The subspace $x^{\wedge} y^{\wedge} z$ which is the inhabited space at the present time is extended into an event which here is a quadrivector, following the duration vector $\mathbf{t}$ which goes continuously from past to future. In this way, the present experienced space is stressed by encountering causalities. One comes mechanically from the past; the other comes from the future, as a retrograde causality fastened to finality. The latter is thus more energetic than mechanical. 
domain, i.e. the attitude of the cell, and the intensive magnitudes, the moving forces. Physically, the same architectonic could depend on a dialectic between topology relating to discrete molecules themselves, and topology relating to the intermolecular physical vacuum which is a single continuous medium.

In this way, from 1900 to 1922 , the mathematician Elie Cartan, developed the Grassmann concept relating to the exterior product [65]. He did it in a direction which was applied by Kiehn's theory of Topological Thermodynamics $[66,67]$. This theory makes it possible in particular to describe the intermolecular physical vacuum.

According to Kiehn, (2012, [68]), an initial contrast appears between molecules which are distinct particles made up of distinct ingredients and waves which are statistical sets of indistinguishable wavelets. The Grassmann theory of 1-forms makes it possible to build a topology of distinct subsets such as physical particles. And Grassmann extension can apply to the n-1-forms of current density, making it possible to build a topology of indistinguishable subsets which obey the wave equation $^{15}$. These two topologies coexist and their coexistence can correspond to the active coexistence of causality order and sense order.

The non-discrete topology relating to thermodynamic wave phenomena allows an interaction with discrete topologies relating to particles. This interaction influences the creation and evolution of the topological structures of discrete particles. This corresponds to the idea of Prigogine on the emergence of the dissipative structures.

In this way, in the living cell, the supra-mechanism joining together causality order and sense order may also be understood through the theory of extension. This theory indeed combines the two methods, analytical and synthetic, applicable to these topologies.

\section{The Assumption on a Phase Shift within Psychic Energies}

\subsection{Psychical Energy and the Extensive Character}

The two dependent forms of psychic energy are moving forces and potential, or attitude. Through the background structure of the physical vacuum, psychical moving forces could be related with biological moving forces. According to Jung, they have also an extensive character to which is joined an imaginary mass, noted for example i.m. It appears possible that such an imaginary mass could fasten physically to bosons moving in the extracellular medium. This can generate a topological-

\footnotetext{
${ }^{15}$ The wave equation, produced for the electron by PAM Dirac in 1928, combined relativity with quantum mechanics. It related the magnetic moment to the angular momentum ascribed to a spinning motion.
}

structure of discrete particles, able to affect the local structure of the medium with a character, (Montagnier, 2010, [69]). In its turn, under certain conditions of reiteration and magnetic environment, this character could become a symbol which causes there an archetypal image to be. The latter should naturally apply to the psychic potential, (or attitude), of the cell.

\subsection{Physical Phase Shifts due to Fluxions}

The most powerful method of investigation that humanity has achieved, the infinitesimal analysis, was born in Newton's mind from his consideration of fluxions ${ }^{16}[70]$. These fluxions relate to the variations of flows, or currents, including electric currents.

When a voltage $v$ is applied to the ends of an inductor $L$, the flow of the electrical current $i$ has a fluxion noted $\mathrm{d} i / \mathrm{d} t$. This fluxion produces a counter-potential at the ends of the inductor, noted $V=L \mathrm{~d} i / \mathrm{d} t$, which delays the current flow $i$ : The inductive magnetic effect of an inductor makes the current $i$ tend to be physically delayed with respect to the applied tension $V$. On the other hand, when a current $i$ passes to a capacitor $C$, the flow of voltage $V$ to its terminals presents a fluxion noted $\mathrm{d} V / \mathrm{d} t$. This fluxion is proportional to the circulating current $i$, according to $i=C \mathrm{~d} V / \mathrm{d} t$. The capacitive electric effect of a capacitor thus makes the electrical current tend to be physically in advance of the tension.

\subsection{The Narrow Psychophysical Parallel}

The existence of a narrow psychophysical parallel is attested by Leibniz, Jung and many others. It could be due to the constituent relationship which was established at the origin between the inorganic world and the organic world, and between the organic world and the psychic world, for a simple law of energy economy [71]. It is assumed that this parallel applies between physical electric phase shifts resulting from fluxions, and psychic energy phase shifts resulting from perception modes.

\subsection{That which Engenders Results from a Dialectic of Opposites}

The philosopher Hegel affirmed that any magnet shows the nature of polarity in a simple and naive way [72].

\footnotetext{
${ }^{16}$ Fluxion is the word Isaac Newton chose in 1665 , to name what is the instantaneous rate of change within a quantity which runs according to a flow. This fluxion is involved in the infinitesimal calculus which makes it possible to find the fluxion of a given flow, as well to find the flow of a given fluxion. Thereafter Leibniz called flow the function $\mathrm{f}$ and fluxion the derivative $\mathrm{d}$, thus opening to science the general topic of the finite-infinitesimal contrast. When philosophers like Bergson [16], insisted nevertheless on using the word fluxion, it was because it implies the considerable efforts which have being carried out towards, and in, the unconscious psyche of Newton, before bringing from it the formidable rational tool which is the infinitesimal calculus.
} 
Behind its simple appearance, magnet bipolarity reflects an original duality. This duality is dynamic and that dynamic makes it possible for nature be the principle which engenders.

The philosophy of nature holds a fundamental idea here. As the mathematical theory of Grassmann was partially founded upon this philosophy of nature, it had to include the idea that the natural principle which engenders results from a dialectic of contrasts, or opposites. The same concept also appears as fundamental in the psychologies of Freud followed by Jung. In this way unconscious nature with an objective horizon is always made up of complementary pairs of opposites. And a thing can exist psychically in the world only if it is present with its opposite, which implies a psychic energy of relation.

\subsection{The Three Phases of the Psychic Energy of Relation}

According to the fundamental idea recalled by Hegel about the example of the magnet, Schelling, in his philosophy of nature, $(1800,[73])$ had thus observed in nature a magnetic active phase which corresponds directly to what the magnet bipolarity conceals.

Schelling said this magnetic phase has a psychobiological effect which is sensitivity to figures. This sensitivity should result from a suggestion effect, arising from the force of imagination ${ }^{17}$ linked itself to the dynamic concept of opposition, (ego/non-ego, being/non-being, reflection/projection) [74]. In the thing's natural state, the suggestion effect should result in an unconscious tendency to harmonization with what is the case.

Schelling also observed a second active phase in god agreement with the same opposition principle. It is the electric phase which draws its generating capacity from the existence of two opposed electricities, resinous, (negative), and vitreous, (positive). This electric phase should cause an automatic excitation, or irritability, as biologically shown in 1791 by Galvani [75].

These two active phases in perception, biomagnetic sensitivity and bioelectric irritability, address a receptive, or passive, phase, resistance or inertia.

\subsection{Cell Status}

Cell status can be determined starting from these three phases. Cell state is defined classically as the overall activation level which modulates the signaling paths, in order to ensure the cell's adaptation to its environmental fluctuations. Such a definition is more complete if the cellular psychic energy with its due temporality is in-

\footnotetext{
${ }^{17}$ Force of Imagination operates by unconscious mimicry as soon as the true sense of the natural being is the active relationship: this self-similarity generates similar laws and likenesses in nature.
}

cluded.

\subsection{Temporality of the Three Phases of Psychical Energy}

1) The psychic energy phase which results from sensitiveity is defined as biomagnetic. Application of the psychophysical parallel endows the biomagnetic phase with a psychic potential which is ahead of moving activation forces. The cell attitude is then in advance of the psychic moving forces which are linked to the mediators' activetion forces relating to signaling pathways.

2) The psychic energy phase which results from irritability is defined as bioelectric, or galvanic. The application of the psychophysical parallel endows the bioelectric phase with a psychic potential, (i.e. a sum of being + non-being that becomes an overall attitude), which is late behind the real currents of activation forces: The galvanic excitation propagates over the field of psychic forces of activation without immediately affecting the cellular attitude.

3) The psychic energy phase which is receptive, or passive, makes these moving forces systematically encounter resistance. This resistance, or inertia principle, should aim to return excitation to level zero, as Freud stipulated [76]. Freud said it was as if any organism, cellular or not, sought to return to an inorganic level.

4) So the temporality of the three phases of the cellular psychic energy presents a dialectical polarization between past and future. As in the case of electric circuits, this temporality can be manifested as the appearance of a phase shift between potential status and moving forces. Its dynamic is fastened to the principle which engenders the actions.

The phase shift angle $\Phi$ can be represented geometrically, in a very similar way to the representations of physics. It is stated that in the Argand-Gauss complex plane, the axis " $i$ ", (which is in fact the axis of $\sqrt{-1}$ ), is the "imaginary" axis which carries the pure psychic potential and its temporality, late or early. Perpendicular to it is the "real" axis which carries the currents of activetion forces associated with the psychic moving forces. Figure 5 shows then that the temporal difference between sensitivity and irritability in cellular perception results in opposite phase shifts, $+\Phi$ and $-\Phi$ '.

5) It follows from the psychophysical parallel that the three phases of the psychic energy could be respective with the three bioelectromagnetic phases of the cell exchanges. As the three basic components of the atoms are the protons, the electrons and the neutrons, the three phases of the psychic energy can be referred logically to the exchanges, or to the moving structures, of these three kinds of physical particles. 


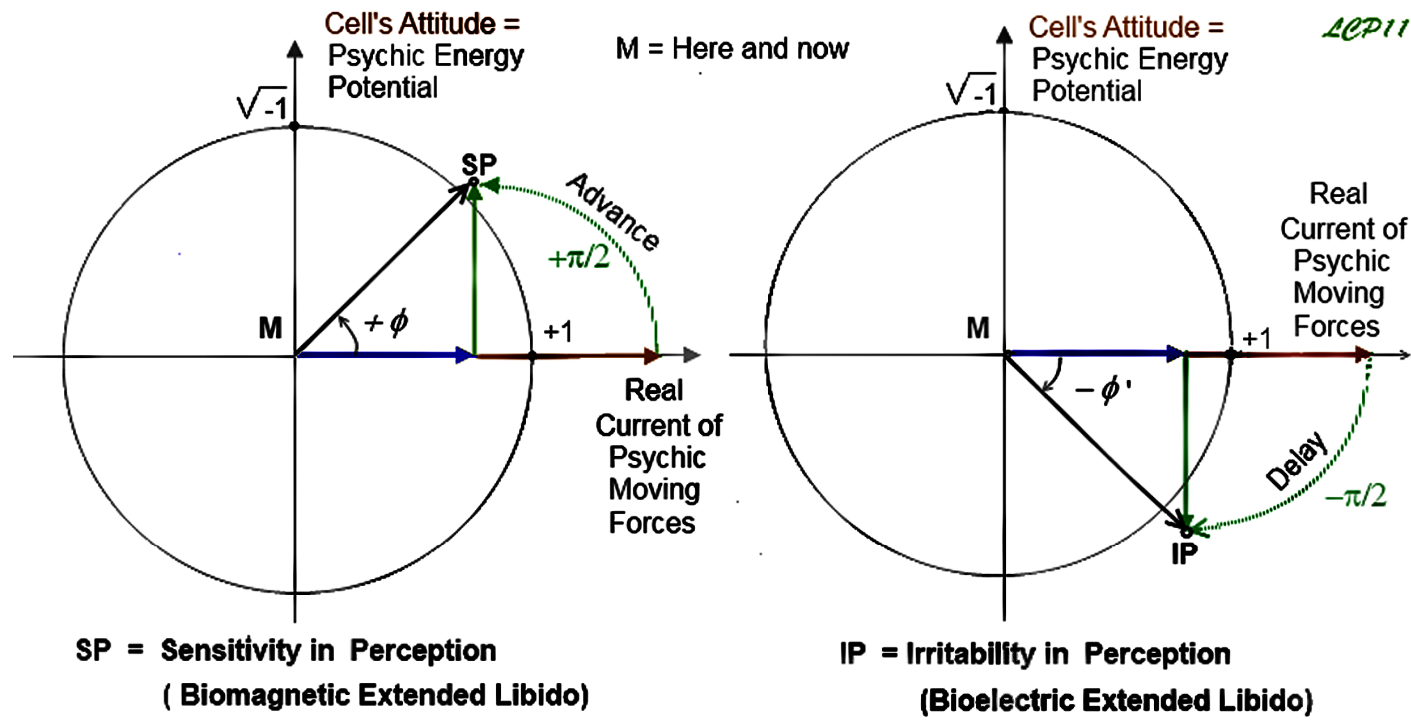

Figure 5. Temporal Difference between sensitivity and irritability in perception. The real horizontal forces starting from the center $M$ correspond to the receptive phase of the living substance which is its resistance. This psychobiological resistance labels the "real" axis of the complex plane because it has no imaginary influence. Its link with the stress due to extension, however, influences the phase shift appearing between potential psychic energy, (carried by the "imaginary" axis) and the psychobiological currents of forces (carried by the "real" axis). This phase shift is an advance characterized by an angle $\Phi$ in the case of a suggestion effect resulting from the sensitivity in perception, SP, (left part of figure) or a delay, characterized by an angle $-\Phi$ ' in the case of excitation resulting from irritability in perception, IP, (right part).

\subsection{Proton Exchange and Biomagnetic Psychic Phase}

It is assumed that the protons exchange and structure correspond to the "magnetic phase" of the bioelectromagnetic energy relation. Protons are linked to the relative acidity of the medium which is measured by a $\mathrm{pH}$ that seems to be independent of the magnetic field. But it is possible to observe that the magnetization of water involves a slight alkalinization. This is explained by coalescence plus a degasification effect which is a proton consumer. In addition, the paramagnetism ${ }^{18}$ of hydrated protons in the aqueous medium is structurally sensitive to the applied magnetic field. As a result, cellular perception of this aqueous structure can have an effect on cell attitude [8].

Biomagnetic perception causes a potential of advanced waves. While binding to the psychic structure of the cellular unconscious, this potential corresponds to the same principle of the force of imagination which produces a suggestion. As a matter of fact, the suggestion effect has a magnetic analogy which had already been announced

\footnotetext{
${ }^{18}$ Paramagnetism corresponds to a magnetization in the same direction as the applied magnetic field: as the rotation axis of the $\mathrm{H}^{+}$proton is that of revolving electricity, it is also a magnetic axis which follows the applied magnetic field. However, the hydrogen bonds which ensure the structure of water have defects, with an excess proton, $\mathrm{H}_{3} \mathrm{O}^{+}$, or lacking a proton, $\mathrm{OH}-$, forming chains. The structuring of these aqueous conducting chains has been shown to be sensitive to a magnetic field, $[77,78]$.
}

by Paracelse, (1603, [79]): "Suggestion gives to man a capacity similar to that of the magnet on iron." The effect of suggestion results in a change in psychic attitude which is already present before any change in moving forces. In that case, cell attitude moves ahead of moving forces.

\subsection{Electron Exchange and Bioelectric Psychic Phase}

It is assumed that electron exchange corresponds to the "electric phase" of the bioelectromagnetic relation energy. An essential element within life processes, electron exchange corresponds to oxidations, (electron losses), or reductions (electron gain). This oxidation-reduction is measured by the redox potential, and more precisely by the redox which is a function of $\mathrm{pH}$, that is the $\mathrm{rH} 2^{19}$. Antioxidant agents buffer the redox state. They also bring in the cell information able to activate the components of the signaling paths which are accorded to redox signaling [80].

Bioelectric, or galvanic, perception causes forces with delayed waves. While binding to the psychic moving forces of the cellular unconscious, it corresponds to the

\footnotetext{
${ }^{19} \mathrm{rH} 2$ and Redox: potential the relation between the $\mathrm{rH} 2$, the $\mathrm{pH}$ and the Redox potential $\mathrm{E}$ is given by the Nernst formula: $\mathrm{E}=0.03(\mathrm{rH} 2-2$ $\mathrm{pH}$ ). The $\mathrm{rH} 2$ is measured from zero to 56 , average 28 . For $\mathrm{rH} 2=0$, a completely reduced state, there is solution overloaded in electrons. For $\mathrm{rH} 2=56$, the solution is completely oxidized.
} 
same principle of excitation, (or irritability).

Thus the bioelectric currents which, however, consist of ion flows are involved in the cellular dynamics. They are involved in the healing of wounds and tissue regeneration, as well as in the directional movement of cells known as galvanotaxis. Cells can respond by a movement in electric fields too weak to act mechanically on them but having an indirect effect on intracellular calcium level, $\left(\mathrm{Ca}^{2+}\right)_{i}$ [81]. This effect is necessarily due to a bioelectric perception of the cells' external medium making them actively excited. This fact can be explained by psychic moving forces acting upon activation forces of mediators of the calcium signalsome. Another example is leucocyte chemotaxis: these white cells manage to leave the blood by migrating through junctions of the endothelials cells, to move towards inflammatory sites where they are attracted by exciting factors [82]. On this occasion, but after an incubation time which corresponds to the delay in their psychic potential on moving forces, these leucocytes can change their form and function and become macrophages.

Another example is inhalation of air negative ions, (of $\mathrm{O}_{2}$-type), by animal organisms. Little by little this inhalation of electricity in the air comes to stimulate the antidiuretic hormone, or vasopressine, which appeared contradictory to the fast diuretic effect of negative ions. Olivereau, $(1973,[83])$ showed that the equivalent of an exciting perception acts at once and produces a diuretic effect, while variation of the unconscious psychic structure on the hypothalamus level needs around twenty days of daily treatments to compensate and bring back diuresis to its normal value. Métadier, $(1978,[84])$ added that this slow rebalancing is characteristic of the bioelectric, (or galvanic), secondary action of negative ion inhalation. Its possible progressive integration in the psychic potential thus lags behind the psychic moving forces.

\subsection{Roles of Neutrons and Receptive Phase}

In atoms, the role of neutrons is mainly to form couples called nucleons within the atomic nuclei with protons. Their receptive role is not an exchange role but a buffer role which dampens the wave fluctuations. What could correspond at the cellular psychology level is the recaptive, or passive, phase of unconscious energetics whose general role is resistance to change. It happens physically by means of a damping of any stimulation waves, through inertia, gravity and medium viscosity.

In psychology, in 1895, Freud [76], had perfectly observed a psychobiological resistance which must be broken during psychotherapy in order to reveal the hidden conflicts. In Freud's opinion, the biological material of this resistance was what corresponds to the nature of sexual energy. But more generally the resistance suitable for life in general could be that of the receptive phase of unconscious psychic energy. As in physics, this psychic resistance is exerted at the present time.

\subsection{Electromagnetic Modulation of the Psychic Phase Shift of the Cell}

After exposure to defined electric and magnetic fields, the structure of the extracellular aqueous medium may be changed so that a theoretical change of temporal phase shift can appear in cellular psychology. This phase shift exists in the energetics between psychic potential and moving forces. It can be represented in the Argand-Gauss complex plane, as shown in Figure 6.

With a different phase shift angle $\Phi$ the event perception in the being-envelope will translate into a different variation in sense order. So a modulation of the temporal phase-shift angle may change the cell's state and attitude. A progressive change in the life of a cell belonging to a lesion site or an injured tissue could be pulled in a therapeutic direction, by means of medium exposure to electric and magnetic fields having specific waveforms.

Because of the existence of a temporal phase shift $\Phi$ between an imaginary potential and real moving forces, there are always certain frequencies and waveforms

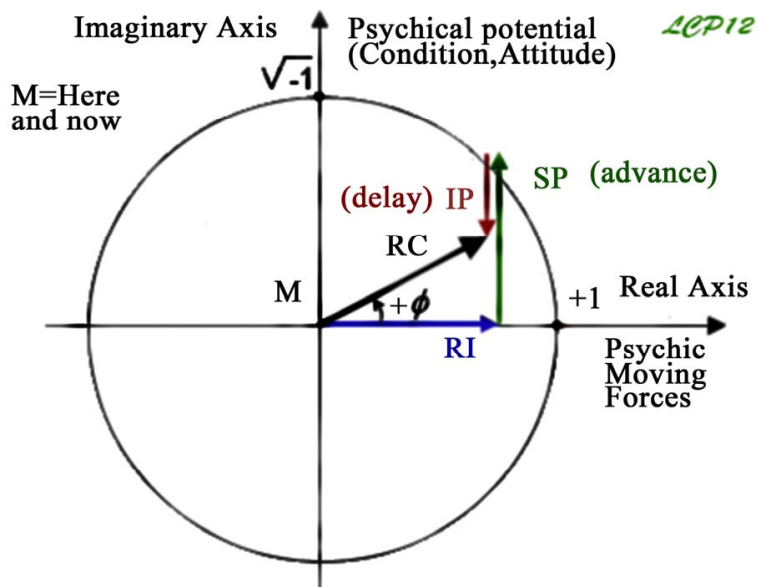

Legend of symbols:

$\mathrm{IP}=$ Irritability in Perception $\mathrm{SP}=$ Sensitivity in Perception

$\mathrm{RI}=$ Resistance and Inertia $\mathrm{RC}=$ Resulting Compound $\Phi=$ Phase Shift angle

Figure 6. Temporal phase shift in cellular psychology. The physical phase shift is due to phase differences in the energy of the relation. Sensitivity in perception, SP, corresponds to an advance, according to a vector parallel to the imaginary axis. Irritability in perception, IP, corresponds to a delay according to a vector directed in the opposite direction of the imaginary axis. Psychic resistance corresponds to physical resistance to moving forces according to a vector directed along the real axis of the complex plan. The Resulting Compound, $\mathrm{RC}$, is a vector presenting a phase shift angle $\Phi$ with the real present axis. 
which will have a better result than others under experimental conditions. This means that the idea of allotting more effective frequencies to the effect of a technical resonance, (such as cyclotronic resonance [85]), cannot always be confirmed by the experimental facts.

\subsection{Resonance}

On the other hand it can be useful to discover what kind of magnetic or electromagnetic wave forms may support resonance in cellular psychology, depending on cell varieties. When the compensation of advances and delays between attitude and forces leads to a null phase shift, psychic forces may become entirely real, as showed in Figure 7.

\section{The Event and the Felt Space}

\subsection{The Proximity and the Felt Space}

According to Husserl, Phenomenology [86], the domain of the constitution of the flesh is proximity. This philosophical idea becomes clear since proximity is a concept relating to the active presence of the bodily unconscious in a place where the flesh already knows it is a body, as Merleau-Ponty suggested [41]. What is felt remotely through the extension property of the organism can participate in this proximity, as Husserl specified. Proximity can thus be a depth which can be perceived by any organism, even unicellular. Depth is perceived with the help of the temporal thickness $t$ which is the main

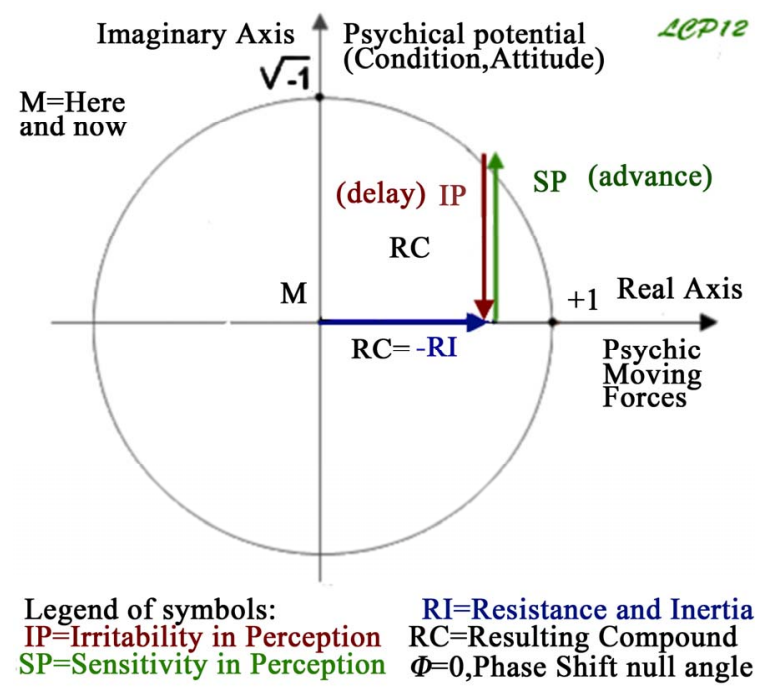

Figure 7. Resonance in cellular psychology. Under the psychic condition of resonance, the potential lead on moving forces which is due to sensitivity, (SP) and its delay due to irritability, (IP) are compensated. As a result, the psychic energy vector, (RC), can endeavor to entirely overcome resistance and inertia vectors, $(\mathrm{RI})$, according to a real activation status at the present time. line of the event $x^{\wedge} y^{\wedge} z^{\wedge} t$. Depth is made tangible for an organism through its gesture, (-taxis), or through the kind of mechanical vibrations which reach it [87].

According to Art sciences, a felt space is a space which forms an event in the individual proximity. When Cézanne, while painting Mount Sainte-Victoire, said: "If I move just a little, I will have months more of work!" at the distance from which he was painting, a few steps to the side could not have changed anything in the shape of the mountain. But the felt space of a landscape can be strongly redefined by a small variation in angular position. This means that the aesthetic felt space is of another kind than shape and escapes from any geometry, because of the nature of proximity which is linked to bodily unconscious. For the painter felt space is an event whose conditions (of constitution and perception) can be the very object of the painting [88].

It is not every mountain that offers a vision that becomes an event in the proximity of the organism. It has to fill an inherent emptiness, as the French philosopher Barbaras, the successor of Merleau-Ponty, observed [89]. Mount Sainte-Victoire appeals sensitivity to adjust itself to the meaning of the mountain, because it returns its observer to the inherent enigma of life ${ }^{20}[90]$. Thus any esthetic event coming from the environment can only be felt as a response to the inherent emptiness of an organism's nature.

For a cellular organism, this idea could be biologically translated as follows: The topological structure of the intermolecular aqueous space forms an event when the $4 \mathrm{D}$ extension of the cell's magnitudes acts as a non-being on the unconscious potential and thus modulates the sense order which is accorded to the cell's state. The condition of this event is that the structure of non-being should fill something in the inherent emptiness of the living being. Such an idea can apply to medical physiotherapy.

\subsection{Cellular Stimulation}

Events whose framework results from a medium exposure to a magnetic field, MF, or an electromagnetic field, EMF, are not simply due to the causality of mechanical impacts on the membrane's curvature and receptor levels. There is also a mechanical impact on the topological structure of the aqueous extracellular medium, whose possible effect is to redefine the external space the cell can feel through its extension property. The impact of an event upon sense order exists only when it fills something in the inherent emptiness of the living cell. This inherent emptiness seems to be amplified in cells be-

\footnotetext{
${ }^{20}$ Life's inherent enigma is this extra factor which makes the difference between the structure of interaction forces in the intermolecular physical vacuum and what can be still be called the ether.
} 
longing to injured tissues or pathophysiological states.

Sense order being the terrain where the activation forces due to causality order are growing, it follows that a change in the event framework leads to a variation in sense order so that an overall stress is exerted on the moving forces and thus on the intracellular chemical routines which result. In this way, little by little, in session after session of MF or EMF stimulation, everything that is perceived is passed, through repetition, to bodily unconscious. This way an effective and durable change in cellular behavior could be induced in a therapeutic direction.

\subsection{A Biological Field of Application}

The physicist agrees with the anti-symmetry of the bivector in the Grassmann theory, noted as: $x^{\wedge} y=-y^{\wedge} x$, when he considers the natural anti-symmetry: matter is a system of complex waves which is never completely symmetrized by the ordinary reflection that imagesymmetry can offer. It follows that any system must evolve, confronted by a double problem of harmony and melody [91].

The harmony problem concerns coherence in parallel with the wave system. The melody problem concerns coherence in series, along the thread of history. Any event tends to vary the chord, which can result in a contribution or loss of coherence. This phenomenon is involved in biology, as it is involved in thermodynamics and electromagnetism.

The exposure to a magnetic field, MF, of an aqueous medium tends to make its topological structure vary [8]. There physically results a reduction in impurities by flocculation, and a reduction in the medium topological viscosity [92]. If the medium is an extracellular medium, such an event may bring about a contribution or loss of coherence within the cells, according to their type, state and condition.

On the other hand, the cells which thrive in a viscous and charged medium undergo a loss of coherence after a magnetic exposure of their aqueous medium. The fact is that these cells are generally those of pathogenic microbes, whose population density can thereby be reduced. Conversely, applying MF to some lesion sites tends for the same reasons to bring about coherence in the cells, supporting the therapeutic action [93].

The suggestion effect which results from biomagnetism by a magnetic field can strongly affect the attitude of in vitro cultured neurons: after $15 \mathrm{~min}$ of exposure under a static MF of 2000 Gauss, human neurons FNC-B4 show a spectacular change of morphology, in a coherent manner, with induction of remodeling and differentiation, as Pacini observed, (1999, [94]). More generally, the MF and EMF bioeffects depend on the type, state and condition of the cells. They are less spectacular for collective or aggregated cells, such as cells arranged in rows.

\subsection{Example 1: The Reduction of the Populations of Various Pathogenic Microbial Agents}

While acting on the structure of extracellular space, MF has effects on the microbial populations. Microbial vital space is generally in neutral to alkaline $\mathrm{pH}$, and slightly reduced $\mathrm{rH} 2$. For example the staphylococcus lives at its best in $\mathrm{pH}=7.3, \mathrm{rH} 2=19$ and Bacterium Coli in $\mathrm{pH}=$ $7.3, \mathrm{rH} 2=15$ [95]. The MF exposure of a culture creates a stimulation which often produces biphasic effects. For example there is an increased growth of the population of the staphylococci over a few hours, followed by a decrease, and finally by a re-normalization [96]. On the other hand the population of saccharomyces present in orange juice is reduced by 25,000 cells per $\mathrm{ml}$ at 6 , after magnetizing. Hofmann, (1985, [97]), observed that these effects of MF on the microbial populations depend on the MF waveform and intensity, as well as on properties (electric resistivity Rô, thickness, etc.) of the food containing the microbes. The low resistivity Rô supports the presence and the resistance of their populations.

\subsection{Example 2: The Repair of Injured Tissues}

Cartilage cells, called chondrocytes, occur at scattered sites through the cartilage which is composed of a dense network of collagen fibres embedded in a firm, gelatinous ground substance. The exposure to EMF during 24 $\mathrm{h}$ of a collagen gel with its living chondrocytes resulted in a gel which had already become more hydrophobic and less suitable for enzymatic degradation. After three weeks of exposure, Chang, (2009, [98]), observed an accentuated chondrocyte proliferation associated with a lower production of glycasaminoglycan, GAG, as well as a reinforced gene expression, mARN, for aggrecan and collagen. So the exposure time to EMF changes the effect.

In the stimulation by EMF of two antioxidant enzymes, (superoxide dismutase and glutathion peroxidase) in the rat, the bioeffect also varies according to the time of exposure. The antioxidant activity increases during the first week then re-normalizes after three weeks of exposure, Artenie, (2007, [99]) indicated. Because the Chang and Hofmann results relate to cells cultured in a given medium and not to complex organisms like rats, it is possible to say that the change of antioxidant bioeffect after exposure to EMF happened initially at the level of the cell psychic energetics, and not at the level of the sympathetic nervous system of the rat organism. 
Many studies indicate that stimulation of the cells of injured tissues by pulsed EMF can produce anti-inflammatory and analgesics effects. But that is not always true. Thus Aktas, (2007, [100]) did not obtain any improvement in the "subacromial impingement syndrome" after treatment by exposure to PEMF. To explain his failure, Aktas noticed that no known optimal dosimetry exists for pulsed EMF treatments in the range from 2 to 100 Gauss, 1 to 100 Hertz, daily sessions of $1 / 2$ to $1 \mathrm{~h}$, during 1 to 3 weeks. His choice of pulsed EMF signal, (30 Gauss, 50 Hertz, with unknown waveform), proved only to be inadequate to repair the studied type of injured tissue.

\subsection{Cellular Resistance}

Detailed descriptions by patients showed the existence of some "cellular resistance" which rises after some sessions to oppose the dictation of the applied PEMF treatment. It also appears during animals' treatment, as De Mattei (2007, [101]) observed. To stop the genetically irreversible evolution of the articular cartilage in the old Dunkin-Hartley pigs, the chondrocytes stimulation by PEMF must be important in duration, and to be lengthily and patiently repeated, because a cellular resistance opposes the dictating of the treatment. Insofar as the most elementary psychic material is the feeling, cells have probably a psychic part which is an elementary material unconscious. This way, the evolutionary change under dictation of a repeated event, is not done without a natural attempt to get back to the previous order, because material unconscious is former to the present cell status with its molecules organization [10]. In that way, topological nuances which integrated the being-envelope during PEMF treatment meet consist of a temporal thickness. Within this temporal thickness the constant modulation of the signalsome ensures all at the same time both the cell endurance and its possible adaptation to the changing world. Temporal thickness is what allows the organism to be enduring, rising all at the same time both a resistance to events dictation and an adaptation faculty.

\section{Conclusions}

It is assumed that any living cell has a psychic energy which consists of psychic potential and moving forces. The psychic potential corresponds to the cell attitude, (or its condition, its bio-availability). As it is a (being + nonbeing) sum, it therefore depends on the physiopathologycal state of the tissue as well as on local medium conditions. Within the energetics of the cell, a temporal phase shift can frequently exist between psychic potential and moving forces. When the psychic potential is not in line with moving forces, their action upon physical activation forces is less effective.

It is assumed that this temporal phase shift within psychic energy is logically modulated by the perception of an event which is permitted by the extension property of the cell. A structural variation in the extracellular medium can result from its exposure to an electromagnetic signal. The resulting event is then defined as a Grassmann number, $x^{\wedge} y^{\wedge} z^{\wedge} t$, where the cell's temporal thickness $t$ is the main extension line.

It is assumed that the perceived event includes two active phases which are suggestion, (biomagnetic phase), and excitation, (bioelectric phase). Suggestion pushes psychic potential ahead of psychic moving forces. Conversely, excitation pushes psychic forces ahead of psychic potential, or attitude.

In addition, the reiteration of the signal waveform, according to the reiterated wave trains, can give a particular character to the structure of the medium. This character is assumed to be transferred with the unconscious psychic energy conversions. In relation to the life and sense archetype, this could bring about sense contribution in the life of the cell.

It would be through this qualitative trilogy, (suggestion, excitation, character), that the stimulation of specific cells by means of exposure to any electromagnetic signal offers no certainty of bioeffects. A given physiopathological state can be treated effectively only if the waveform of the applied EMF tends to reduce the existing phase shift in the cellular psychic energy, and to bring about sense within it: exposure of injured tissue to such a good specific waveform appears necessary to achieve success with treatments by MF, or pulsed EMF.

\section{REFERENCES}

[1] J. Hanoune, "Signalisation Cellulaire," Encyclopédia Universalis, Paris, 2005.

[2] J. Wang, P. Cieplak and P. A. Kollman, "How Well Does a Restrained Electrostatic Potential (RESP) Model Perform in Calculating Conformational Energies of Organic and Biological Molecules?" Journal of Computational Chemistry, Vol. 21, No. 12, 2000, pp. 1049-1074. doi:10.1002/1096-987X(200009)21:12<1049::AID-JCC3 3.0.CO;2-F

[3] M. J. Berridge, "Cell Signalling Biology, Introduction," Portland Press, 2008. www.cellsignallingbiology.org

[4] S. Ji, "Chapter 12.13, the Cell Force: Micrroarray Evidence," In: S. Ji, Ed., Molecular Theory of the Living Cell: Concepts, Molecular Mechanisms and Biomedical Applications, Springer, New York, 2012.

[5] M. W. Kirschner, "The Meanings of Systems Biology," Cell, Vol. 121, 2005, pp. 503-504.

[6] C. Piquet-Pelloce, "Intégration des Réseaux de Signalisation," SRAIC, University of Rennes 1, 2010. 
[7] D. Skrbina, "Epicurus and the Atomic Swerve," In: D. Skrbina, Ed., Panpsychism in the West, MIT Press, Cambridge, 2005.

[8] S. B. Mcgrayne, "The Atomic Philosophy of the Early Greeks," In: S. B. Mcgrayne, Ed., Atom, Encyclopcedia Britannica, Chicago, 2011.

[9] P. Davies, "Quantum Factor," In: P. Davies, Ed., God and the New Physics, JM Dent \& Sons Publishers, London, 1987.

[10] P. Le Chapellier and B. Matta, "Cellular Perception: When the Cell Model Includes a Sense Order Which Ensues from a Philosophy of Nature, the Signaling and Epigenetics Effects Which Can Result from Exposure to Magnetic Fields Are Described Better," Neurosciences and Medicine, Vol. 2, No. 3, 2011, pp. 161-177. http://www.scirp.org/journal/nm

[11] S. Frisch, "Le Sommeil de Rêve Revu par la Psychanalyse, AEPU Le Sommeil en Neurologie, "Centre Hospitalier de Luxembourg, Luxembourg, 2006.

[12] H. Lodish, A. Berk and S. L. Zipursky, "Eukaryotic Gene Control," In: Molecular Biology, 4th Edition, WH Freeman, Ney York, 2000.

[13] Z. Wang, A. Sarje, P.-L. Che and K. J. Yarema, "Moderate Strength (0.23 - $0.28 \mathrm{~T})$ Static Magnetic Fields (SMF) Modulate Signaling and Differentiation in Human Embryonic Cells," BMC Genomics, Vol. 10, 2009, p. 356. http://www.biomedcentral.com/1471-2164/10/356 doi:10.1186/1471-2164-10-356

[14] C. G. Jung, "Uber die Energetik der Seele, Trad. fr.: L'énergétique Psychique," Le Livre de poche, LGF, Paris, 1996.

[15] C. G. Jung, "The Archetypes and the Collective Unconscious, Translated by RFC Hull, Bollingen Series," Princeton University Press, Princeton, 1990.

[16] H. Bergson, "La Pensée et le Mouvant," Quadrige, PUF, Paris, 1987.

[17] C. G. Jung, "Pattern of Behaviour and Archetype," In: Der Geist der Psychologie, Eranos Conference, Eranos Jahrbuch, 1946.

[18] A. Schopenhauer, "The World as Will and Representation, Vol 1, Translation by J. Norman \& Al of Die Welt als Wille und Vorstellung," Cambridge University Press, Cambridge, 2010.

[19] C. G. Jung, "La réAlité de l'âme, T1, Structure et Dynamique de L'inconscient, La Pochothèque, Livre de poche," Librairie Générale de France, Paris, 2008.

[20] C. Gillain, "La théOrie Qualitative de Poincaré et le Problème de l'intégration des Equations Différentielles," In: H. Gispert, Ed., La France Mathématique: La Société Mathématique de France, 1872-1914, SFHST-SMF, Paris, 1991, pp. 215-242.

[21] J. Mawhin, "The Early Reception in France of the Work of Poincaré and Lyapunov in the Qualitative Theory of Differential Equations," Philosophia Scientiae, Vol. 1, No. 4, 1996, pp. 119-133.

[22] T. Fuchs, "Body Memory and the Unconscious," Psy- chiatrishe Universitatsklinik, Heidelberg.

[23] J. Russon, "The Bodily Unconscious in Freud's 'Three essays'," In: R. Freud, Ed., Psychoanalysis Trough Philosophy, SUNY Press, Albany, 2004, pp. 33-50.

[24] C. G. Jung, "De la Notion D’archétype,” In: C. G. Jung, Ed., Les Racines de la Conscience, Le Livre de Poche, LGF, Paris, 1995.

[25] R. L. Descartes, "Discours 6," In: La Dioptrique, Ed., Discours de la Méthode Pour Bien Conduire sa Raison et Chercher la Vérité Dans Les Sciences, Jean Maire, Leyde, Hollande, 1637.

[26] C. G. Jung, "Der Geist der Psychologie, Eranos Conference, 1946, Trad. fr.," In: Racines de la Conscience, VII, Buchet-Chastel, Paris, 1971.

[27] H. Bergson, "Matière et Mémoire, Essai sur la Relation du Corps à L'esprit," In: Du Centenaire, Euvres, PUF, Paris, 1992.

[28] C. G. Jung, "Psychologie de L'inconscient, Le Livre de Poche," LGF, Paris, 1996.

[29] C. Clement, "Breuer Joseph (1842-1925)," Encyclopédia Universalis, Paris, 2005.

[30] J. Breuer and S. Freud, "Studien über Hysterie, Studies on Hysteria," The Hogarth Press, London, 1955.

[31] C. G. Jung, "La Réalité de L'âme, T1, Structure et Dynamique de L'inconscient, La Pochothèque, Livre de poche," Librairie Générale de France, Paris, 2008, p. 294.

[32] C. G. JUNG, "La Réalité de L'âme, T1, Structure et Dynamique de L'inconscient, La Pochothèque, Livre de Poche," Librairie Générale de France, Paris, 2008, p. 1050.

[33] C. G. Jung, "Epilogue,” In: C. G. Jung, Ed., Psychologie et Alchimie, Editions Buchet-Chastel, Paris, 1970.

[34] J. C. Venter and D. Gibson, "How We Created the First Synthetic Cell. The Assembled Genome Is the Largest Chemically Defined Structure Ever Synthetized in the Laboratory," The Wall Street Journal, Opinion, 26 May 2010 .

[35] C. G. Jung, "La Réalité de L'âme, T1, Structure et Dynamique de L'inconscient, La Pochothèque, Livre de Poche,” Librairie Générale de France, Paris, 2008, p. 295.

[36] M. Merleau-Ponty, "La phénoménologie de la Perception," Gallimard, Paris, 1945

[37] N. Malebranche, "De la Recherche de la Vérité, (Search after Truth)," Belin Frères, Paris, Vol. 3, 1674-1678.

[38] E. Kant, "Analytique Transcendantale,” In: E. Kant, Ed., Logique Transcendantale, Critique de la Raison Pure, (Critique of Pure Reason), Livre II, 1787.

[39] N. Boccara, "La Physique des Transitions, Coll. Que Sais-Je?" PUF, Paris, 1970

[40] C. G. Jung, "La Réalité de L'âme, T1, Structure et Dynamique de L'inconscient, La Pochothèque, Livre de Poche," Librairie Générale de France, Paris, 2008, p 1072.

[41] M. Merleau-Ponty, "La Nature-Notes, Cours au Collège de France," Le Seuil, Paris, 1995. 
[42] A. N. Whitehead, "Science and the Modern World," The MacMillan Company, New York, 1925.

[43] G. Cardano, "Artis Magnae, Sive de Regulis Algebraicis," The Great Art or the Rules of Algebra, Translated and Edited by T. Richard Witner, The MIT Press, Cambridge, 1968.

[44] E. Cousquer, "La Fabuleuse Histoire des Nombres," Diderot Editeur, Paris, 1998.

[45] C. Wessel, "Om Directionens Analytiske Betegning, et Forsøg, Anvendt Fornemmelig til Plane og Sphæriske Polygoners Opløsning. Nye Samling af det Kongelige Danske Videnskabernes Selskabs Skrifter 5, pp. 469-518. (On the Analytical Representation of Direction, Royal Danish Academy of Sciences and Letters)," 1799.

[46] J. R. Argand, "Essai sur une Manière de Représenter les Quantités Imaginaires Dans les Constructions Géométriques (Essay on a Method of Representing Imaginary Quantities)," Annales de Mathématiques, Paris, 1813.

[47] C. F. Gauss, "Selbstanzeige von Theoria Residuorum Biquadraticorum, Commentatio Secunda," Goettingen gelehrte Anzeigen, Werke II, 1831, pp. 169-178.

[48] J. J. Gray, "Gauss, Carl Friedrich," Enc. Britannica, Chicago, 2007.

[49] B. Director, "Carl Gauss's Fundamental Theorem of Algebra," The Schiller Institute, 2002. http://www.schillerinstitute.org/educ/pedagogy/gauss fun d bmd0402.html

[50] D. Wilkins, "Hamilton, Sir William Rowan," Enc. Britannica, Chicago, 2007.

[51] G. W. F. Hegel, "Naturphilosophie, in Encyklopädie der Philosophischen Wissenschaften im Grundrisse, (Philosophy of Nature, Vol. 3, 2nd Part of 'Encyclopaedia of the Philosophical Sciences in Outline)'," 1817.

[52] J. C. Maxwell, "Traité D'électricité et de Magnétisme," Vol. 2, Paris, 1989.

[53] G. Simondon, "L'individuation à la Lumière des Notions de Forme et D'information," Grenoble, 2006.

[54] H. G. Grassmann, "Die Lineale Ausdehnungslehre, ein Neuer Zweig der Mathematik," Verlag Von Otto Wigand, Leipzig, 1844.

[55] A. N. Whitehead, "The Concept of Nature," Cambridge University Press, Cambridge, 1920.

[56] A. N. Whitehead, "Treatise on Universal Algebra," Cambrige University Press, Cambridge, 1989.

[57] D. Flament, "Théorie des Formes et Avènement d'une Nouvelle Discipline des Mathématiques Pures," Selon Hermann Günther Grassmann, Revista Brasileira de Historica de Cienza, Vol. 1, No. 2, 2008, pp. 178-200.

[58] G. W. F. Leibniz, "Lettre à Huygens, du 8 Septembre 1679," In: C. Huygens, Ed., Christian Hugenii Aliorumque Seculi XVII, Uylenbroek Ed, Hagae Comitum, 1833.

[59] G. Bitterfeld, J. Browne and J. Steiner, "Application of Grassmann Algebra to Geometry Using Mathematics," The Role of Mathematics in Modern Engineering: Proceedings of AEMC' 94, 1994, pp. 525-533.
[60] J. Browne, "Grassmann Algebra, Exploring Extended Vector Algebra with Mathematica," Quantica Publishing, Melbourne, 2009.

[61] D. Flament and D. Bekemeier, "Hermann Günther Grassmann, La Science de la Grandeur Extensive," Blanchard, Paris, 1994.

[62] A. N. Whitehead, "Process and Reality," The MacMillan Company, New York, 1929.

[63] J. L. Dorier, "Hermann Grassmann et la Théorie de L'extension," Repères IREM, Vol. 26, 1997, pp. 89-108.

[64] A. N. Whitehead, "Science and the Modern World," The MacMillan Company, New-York, 1925.

[65] E. Cartan, "Leçons sur les Invariants IntéGraux," Hermann, Paris, 1922.

[66] R. M. Kiehn, "Non-Equilibrium Systems and Irreversible Processes, Vol. 1. Non-Equilibrium Thermodynamics," Lulu Enterprises Inc., Raleigh, 2006. http://www.lulu.com/kiehn

[67] R. M. Kiehn, "Non-Equilibrium Systems and Irreversible Processes, Vol. 6. The Universal Effectiveness of Topological Thermodynamics," Lulu Enterprises Inc., Raleigh, 2011.

[68] R. M. Kiehn, "Private Communication,” 2012.

[69] L. Montagnier, J. Aïssa, E. Del Giudice, C. Lavallee, A. Tedeschi and G. Vitiello, “ADN Waves and Water," 2010, in press.

[70] J. J. Gray, "Newton and Leibniz," In: J. J. Gray, Ed., Mathematics, Encyclopaedia Britannica, Chicago, 2011.

[71] R. Huyghe, "La Forme Jette un Pont Entre la Conscience et L'univers," In: R. Huyghe, Ed., Formes et Forces, Flammarion, Paris, 1971.

[72] G. W. F. Hegel, "Philosophie de la Nature. Tome 3; Trad. A. Véra, Ladrange, 1863-1866,” Paris, 1817.

[73] M. Matter, "Schelling ou la Philosophie de la Nature," Comptoir des Imprimeurs-Unis, Paris, 1845.

[74] E. Jalley, "Le concept d'opposition," Encyclopaedia Universalis, Paris, 2011.

[75] R. O. Becker and A. A. Marino, "Electromagnetism and Life," State University of New York Press, Albany, 1982.

[76] S. Freud, "Au-delà du Principe de Plaisir," In: S. Freud, Ed., Essais de Psychanalyse, Trad. J. Laplanche, Paris, 1981.

[77] X. Pang and B. Deng, "Investigation of Magnetic-Field Effects on Water," Applied Superconductivity and Electromagnetic Devices, ASEMD 2009, International Conference, 2009, pp. 278-283. doi:10.1109/ASEMD.2009.5306642

[78] V. F. Kovalenko, A. Bordyuk and S. V. Shutov, "Light Scattering under Magnetic Field," Ukrainian Journal of Physical Optics, Vol. VII, No. 1, 2010, pp. 6-20.

[79] Paracelse, "Paracelse, Euvres Médicales Choisies, Trad. B. Gorceix," PUF, Paris, 1968.

[80] H. B. Shao, L. Y. Chu, Z. H. Lu and C. M. Kang, "Primary Antioxidant Free Radical Scavenging and Redox 
Signaling Pathways in Higher Plant Cells," International Journal of Biological Sciences, Vol. 4, No. 1, 2008, pp. 8-14.

[81] D. Bray, et al., "Cell Movements," Garland Publishing Inc., New York, London, 1992.

[82] C. Deby and G. Deby-Dupont, "Biochimie de L'oxygène, CORD," Université de Liège, Liège, 2006. www.ulg.ac.be/cord/cours.html

[83] J. M. Olivereau and R. Courrier, "Actions de L'ionisation Atmosphérique Artificielle sur L'excrétion Urinaire du Sodium et du Potassium," C.R. Académie des Sciences, Vol. 276, 1973, pp. 777-780.

[84] J. Metadier, "L'ionisation de L'air et Son Utilisation," Maloine s.a. Editeur, Paris, 1978.

[85] A. R. Liboff, "Electric Field Ion Cyclotron Resonance," Bioelectromagnetics, Vol. 18, 1997, pp. 85-87. doi:10.1002/(SICI)1521-186X(1997)18:1<85::AID-BEM 13>3.0.CO;2-P

[86] E. Husserl, "Idées Directrices Pour Une Phénoménologie, T2: Recherches Phénoménologiques Pour la Constitution, Traduction Eliane Escoubas,” PUF, Paris, 1982, p. 178.

[87] M. Merleau-Ponty, "L'œil et L'esprit," Gallimard, Paris, 1964, pp. 17-37.

[88] J. Guiraud, “Espace,” Enc. Universalis, Paris, 2005.

[89] R. Barbaras, "Le désir et la Distance, Introduction à Une Phénoménologie de la Perception," Vrin, Paris, 1999.

[90] R. Gely, "De la Vulnérabilité Originaire de la vie Perceptive à L'évènementialité du Sens: Réflexions à Partir de Merleau-Ponty," Bulletin D'analyse Phénoménologique, Vol. VI, No. 2, 2010, pp. 180-203.

[91] O. C. De Beauregard, "La Notion de Temps," Hermann, Paris, 1962.

[92] J. M. P. Le Chapellier, "La Mémoire Magnétique de L'eau et la Nature Biologique de la Vie, Journées Toulousaines de l'Eau," Salle Osette, Toulouse, 2011.

[93] P. Le Chapellier and B. Matta, "Cellular Perception and Active Penetration Depth for Pain Magnetotherapy," PIERS On line, Vol. 6, No. 3, 2010, pp. 287-292.
[94] S. Pacini, G. B. Vannelli, T. Barni, M. Ruggiero, I. Sardi, P. Pacini and M. Gulisano, "Effect of 0,2 T Static Magnetic Field on Human Neurons: Remodeling and Inhibition of Signal Transduction without Genome Instability," Neuroscience Letters, Vol. 267, 1999, pp. 185-188. doi:10.1016/S0304-3940(99)00362-6

[95] L. C. Vincent, "La Bio-Electronique, Science des Terrains Biologiques," Journées Internationales des Implants Dentaires, Hôpital Lariboisière, Paris, 21 November 1964.

[96] US FDA, "Kinetics of Microbial Inactivation for Alternative Food Processing Technologies," Oscillating Magnetic Fields, Center for food safety and Applied Nutrition, 2 June 2000. www.quantumbalancing.com/news/usda_magnetic_fields .htm

[97] G. A. Hofmann, "Desactivation of Microorganisms by an Oscillating Magnetic Field," US Patent 4524079, 1985.

[98] C. H. Chang, S. T. Loo, H. L. Liu, H. W. Fang and H. Y. Lin, "Can Low Frequency Electromagnetic Field Help Cartilage Tissue Engineering?" Journal of Biomedical Materials Research Part A, Vol. 92, No. 3, 2009, pp. 843-851.

[99] V. Artenie, C. L. Maniu, R. Artenie and M. Caunic, "Electromagnetic Field Influence on Some Antioxidant Enzymes from Rat Blood Serum," Analele Stiintifice Universitatii Alexandru Ioan Cuza, Sectiunea Genetica si Biologie Molecular, TOM VIII, 2007.

[100] I. Aktas, K. Akgun and B. Cakmak, "Therapeutic Effect of Pulsed Electromagnetic Field in Conservative Treatment of Subacromial Impingement Syndrome, Clinical Rheumatology, Vol. 26, 2007, pp. 1234-1239. doi:10.1007/s10067-006-0464-2

[101] M. de Mattei, M. Fini, S. Setti, A. Ongaro, D. Gemmati, G. Stabellini, A. Pellati and A. Caruso, "Proteoglycan Synthesis in Bovine-Articular Cartilage Explants Exposed to Different Low-Frequency Low-Energy Pulsed Electromagnetic Fields," Osteoarthritis and Cartilage, Vol. 15 , No. 2, 2007, pp. $163-168$ 